La formación de los profesionales de la música del siglo XXI desde la perspectiva del profesorado de instrumento musical. Un enfoque internacional Raúl Wenceslao Capistrán

Epistemus - Revista de estudios en Música, Cognición y Cultura, 9(1), 98-118, e030, 2021 ISSN 1853-0494 | https://doi.org/10.24215/18530494e030 https://revistas.unlp.edu.ar/Epistemus Sociedad Argentina para las Ciencias Cognitivas de la Música (SACCoM)

\title{
La formación de los profesionales de la música del siglo XXI desde la perspectiva del profesorado de instrumento musical
}

Un enfoque internacional

\author{
Raúl Wenceslao Capistrán \\ raul.capistran@edu.uaa.mx \\ Universidad Autónoma de Aguascalientes
}

Resumen

En este artículo se presentan los resultados de un estudio que tuvo como propósito determinar las percepciones de los docentes de instrumento de varias instituciones musicales a nivel superior de México y España, con respecto a la pertinencia de la formación musical que están recibiendo los estudiantes para afrontar los retos laborales que les depara el siglo XXI. El estudio fue de corte cualitativo. La recopilación de información se llevó a cabo a través de la técnica de la entrevista semiestructurada. Cinco profesores de varias universidades Mexicanas y cinco del Real Conservatorio Superior de Música de Granada, España, participaron en el estudio. El análisis de la información recabada reveló que, tanto los profesores universitarios como los del conservatorio están convencidos de que los planes de estudio no preparan integralmente a los estudiantes para los retos que enfrentarán en el mundo laboral. Entre las conclusiones, destaca la necesidad de cambios importantes en la formación de los músicos, que incluya, entre otros aspectos, la revisión de los planes de estudio y un mayor énfasis en el desarrollo de la creatividad, la innovación y la autogestión.

\section{Palabras Clave}

educación musical, formación profesional, planes de estudio, mercado laboral, capacitación laboral. 


\title{
The training of 2 I st century music professionals from the perspective of musical instrument teachers
}

\author{
An international approach
}

\begin{abstract}
In this article, the author presents the results of a study whose purpose was to determine the perceptions of instrument teachers from various tertiary music education institutions in Mexico and Spain, regarding the relevance of the musical training students are receiving in preparation for the challenges of the 21 st century. The collection of information was carried out through the semi-structured interview technique. Five teachers from various universities of Mexico and Five from the Royal Conservatory of Music of Granada, Spain, participated in the study. The analysis of information revealed that university and conservatory professors are convinced that degree plans do not adequately prepare students for the challenges they will face in the world of work. Among the conclusions, the need for important changes in the training of musicians stands out, and includes, among other aspects, the revision of degree plans, as well as a major emphasis on the development of creativity, innovation, and self-management.
\end{abstract}

\section{Key Words}

music education, professional education, degree plan, working market, job training.

\section{Introducción}

Tradicionalmente la formación académico-musical a nivel superior de un ejecutante enfatiza la adquisición de conocimientos teórico-musicales, así como el desarrollo de habilidades y destrezas que se vean reflejadas en el dominio técnico al ejecutar un instrumento musical. Así, es más que común ver a los y las estudiantes dedicar horas enteras al aprendizaje del repertorio académico de los siglos XVII, XVIII, XIX y XX. Quienes laboran como docentes en las instituciones de educación musical a nivel superior, diariamente pueden escuchar como gradualmente los y las estudiantes van aprendiendo obras solistas, de cámara y orquestales de Gabrielli, Bach, Mozart, Beethoven, Brahms, Debussy, Ginastera y Ponce, entre una pléyade de compositores validados por la historia de la música occidental. Cómo podría esperarse, el resto del tiempo es dedicado, en primer lugar, a las materias teórico-musicales y, finalmente, a las materias no musicales que tienen como finalidad procurar una formación más integral.

El resultado artístico suele ser bastante bueno y la formación general, por lo 
menos, suficiente. Sin embargo, existe un problema: la formación musical superior no parece estar conectada con la vida real, y es que, el mundo para el que los y las estudiantes son supuestamente preparados (el concertismo y la ejecución de música académica sea de cámara o sinfónica), no es una opción laboral 100\% viable. Cómo explica Higuera (2015, p. 94): "No podemos obviar una realidad: una mínima fracción de los titulados superiores en música se dedican exclusivamente a la interpretación". En otras palabras, el resto de los egresados de las instituciones de educación musical a nivel superior deben obtener sus ingresos a partir de diversas fuentes laborales que incluyen, entre otras, la ejecución de música comercial en eventos sociales, así como en restaurants y bares, sea en grupo o como solista, y, por supuesto, la educación musical en todos sus niveles y ámbitos. Más aún, en muchas ocasiones la fuente laboral ni siquiera está lejanamente relacionada con la música. (Guadarrama, 2013, 2014; Ponce de León y Lago, 2009)

A pesar de esta realidad, todo parece indicar que la formación musical de ejecutantes a nivel superior sigue impartiéndose de la misma manera que se ha hecho durante décadas, si no es que durante siglos (Polanco, 2013; Muñoz, 2018). Por lo anterior, y con la finalidad de tener un primer acercamiento a este objeto de estudio desde la perspectiva educativa, nos propusimos realizar una investigación de corte cualitativo y carácter exploratorio. Así, se propuso conocer las percepciones de los propios formadores de ejecutantes, respecto a la pertinencia y suficiencia de la educación que los futuros profesionales de la música están recibiendo, sobre los retos que estos enfrentarán al incorporarse al campo laboral, y sobre las estrategias que podrían implementar para superarlos. Se espera que la información generada contribuya un poco a la conformación de una base epistemológica, a partir de la cual se promuevan cambios en los criterios que, por tanto tiempo, han regido el diseño de los planes de estudio de las carreras en ejecución musical.

\section{Revisión bibliográfica}

En general, podría decirse que la formación profesional de los músicos de concierto incluye, por un lado, las asignaturas propias de su especialidad, como son: solfeo, armonía, contrapunto, análisis musical, historia de la música, música de cámara, y, por supuesto, instrumento. Por otro lado, dependiendo del programa educativo, se incorporan también asignaturas como: educación musical, seminario de tesis, diseño de proyectos culturales, computación aplicada a la música, redacción, idiomas, etc. Por supuesto, quienes diseñan los planes de estudio procuran que el programa educativo brinde una educación profesional lo más integral posible. Sin embargo, en relación con las materias no musicales, Carbajal-Vaca (2017, p. 2) afirma: "parecieran ser... ajenas a los intereses de quienes han elegido una formación profesional". 
Desgraciadamente, después de haber concluido la carrera, el nuevo profesional de la música se da cuenta de que las opciones laborales, en su mayoría, requieren la realización de una diversidad de actividades, muchas veces, poco relacionadas con las tareas a las que dedicó la mayor parte de su tiempo estudiantil. Es entonces que valora aquellas clases que, de haber sido tomadas con seriedad, le habrían brindado algunas de las competencias necesarias para salir adelante.

$Y$ es que el mundo laboral del músico de concierto se caracteriza por la multiactividad, la intermitencia y la flexibilidad (Guadarrama, 2014). El autor mismo ha conocido profesionales de la música que por la mañana trabajan como integrantes de una orquesta sinfónica, por la tarde dan clases de música y por la noche son integrantes de un mariachi o de un grupo musical que ameniza en un restaurant, bar, club nocturno o en eventos particulares. Por otro lado, la intermitencia se ve reflejada en la eventualidad del trabajo que realizan los músicos que integran esos grupos, ya que dependen de la contratación de terceros. Finalmente, la flexibilidad se evidencia en el involucramiento en actividades laborales que nada tienen que ver con las competencias profesionales que adquirió, como el músico que, para complementar sus ingresos, toma el rol de chofer de Uber en las horas libres. Así, no es de sorprender que Danyew (2015, p. 4) asevere: "el panorama musical del siglo XXI es multifacético y en cambio constante, por lo que requiere que los músicos sean flexibles, bien preparados en estilos musicales y equipados con destrezas musicales diversas".

En el contexto mexicano, Machillot (2018) llevó a cabo un estudio en el que participaron músicos de Guadalajara, Jalisco, una de las ciudades del país más pobladas y con mayor actividad musical, y pudo constatar los aspectos que se han discutido en los párrafos anteriores:

la práctica de esta profesión exige, generalmente, el dominio de distintas competencias (tocar diferentes instrumentos o géneros, entre otras) y la realización de diversas labores ligadas con la música (ingeniero de sonido, profesor de música, etcétera), o bien, implica el combinar la profesión con otras actividades ajenas a la música (p. 257).

Por increíble que parezca, ni siquiera los ejecutantes que logran abrirse paso en el mundo de la música académica orquestal, escapan a la necesidad de poseer una preparación más integral que los dote de un mayor y diverso número de competencias. Como explica Higuera:

La función de las orquestas y las labores que realizan en la actualidad no son las mismas que la que se ejercían hace unas décadas. La función meramente interpretativa no es su única actividad y la realización de proyectos con marcado carácter 
social y educativo, hace necesaria una reflexión sobre la figura del músico, imprimiéndole un carácter más flexible y un perfil más completo y multifuncional (2015, p. 94).

Desgraciadamente, las repercusiones de la situación artístico-musical anteriormente descrita, trascienden los retos puramente laborales del siglo XXI y los aspectos relativos a las competencias que se deben desarrollar para enfrentarlos. Guadarrama (2014) ha señalado un aspecto de vital importancia que deriva del choque con la realidad laboral: las tensiones psicológicas que surgen en el músico que desea realizar la labor que su vocación le dicta, pero debe llevar a cabo trabajos por mera subsistencia. "Como afirma Capilla (2000): "Es imposible hacer un cálculo de cuántas vocaciones se frustran a causa de los impedimentos que pone el medio social, pero probablemente sean más de las que se realizan" (p. 47). En ese sentido, los músicos (al igual que los profesionales de las demás artes) probablemente se encuentra en un estado de mayor vulnerabilidad, pues, como explica Higuera (2015), la satisfacción personal del músico ejecutante, depende por mucho de su felicidad como tal. En ese sentido, Nettl (1995), ha destacado la particularidad de los músicos como un colectivo cuya identidad se construye sobre la base de la aptitud y el talento musical. Por su parte, Davis señala: "la aptitud musical une a este grupo y es la característica definitoria de sus miembros. Cualquier ataque a su imagen como músicos es una amenaza tanto para su identidad personal como comunitaria"(2010, p. 11).

Si bien muchos músicos son capaces de sublimar la vocación no realizada y llevar a cabo actividades laborales ajenas a sus aspiraciones con una actitud positiva, muchos otros viven esta situación de una manera negativa. No es difícil recordar músicos que se han caracterizado por realizar su trabajo de una manera rutinaria, mecánica, carente de interés y pasión y que, cuando se refleja en la docencia, los resultados son verdaderamente deplorables.

En resumen, el mercado laboral del siglo XXI requiere de profesionales de la música que sean capaces de gestionar su carrera y sepan aprovechar los nichos de oportunidad que han surgido como resultado de los cambios sociales y los avances tecnológicos. Así, es crucial diseñar planes de estudio más realistas e integrales que tomen en cuenta el mercado laboral y las necesidades sociales que buscan atender; que reconsideren los perfiles de egreso, y que contengan asignaturas que fomenten la creatividad del estudiante y le proporcionen suficientes herramientas y recursos (Lago y Ponce de León, 2012).

Desgraciadamente muchos programas de educación musical a nivel superior no siguen el modelo arriba descrito. Del mismo modo, los estudiantes de música parecen construir sus carreras musicales más sobre la base de su vocación y de 
sus aspiraciones y sueños, que a partir de la realidad laboral de su entorno (Vilar, 2008).

Más aún, debido a todos los retos que la formación musical entraña y a los desafíos que la vida laboral depara a los futuros profesionales de la música, Ponce de León y Lago (2009) han destacado la importancia de incluir departamentos de orientación (consejería, orientación vocacional, ayuda psicopedagógica, etc.), conformados por expertos en ese ámbito, que puedan apoyar y guiar al estudiante a lo largo de su carrera y concientizarlo sobre su futuro. En ese sentido, Polanco (2013) señala tres argumentos sobre la importancia de la orientación en el ámbito de la educación musical superior. En primer lugar, la obligación de proporcionar al estudiante información veraz y actualizada sobre las opciones laborales existentes y lo que se requiere para acceder a ellas; en segundo lugar, la necesidad que tiene el estudiante de recibir asesoría durante sus años de formación ; y en tercer lugar, contribuir a un proceso educativo exitoso.

Se requiere así de una formación que fomente la apertura del pensamiento, que ofrezca un panorama de opciones laborales más amplio, que promueva la desaparición de tantos "espejismos" que han hecho creer a muchos y muchas estudiantes en la supremacía de la ejecución y en la música de concierto, como el único objetivo digno de perseguir. Como afirma Capistrán-Gracia:

Como se ha visto, existe un gran reto por vencer, y ese reto se encuentra en la vida cotidiana que se desarrolla dentro de las propias instituciones de educación musical a nivel superior. Es vital emprender una campaña de concientización sobre los prejuicios que permean la vida de los estudiantes, los cuales muchas veces se constituyen en verdaderos "espejismos" (por ejemplo, ser famoso, ser admirado por los demás o ser importante) que los llevan por senderos que los alejan de su verdadera vocación e, inclusive, muchas veces los hacen infelices. Esas opiniones desfavorables representan un obstáculo para que los estudiantes puedan tener una formación musical profesional, armónica, equilibrada y bien informada (2019, pp. 96-97).

\section{Problema de investigación}

El medio laboral del siglo XXI requiere de músicos habilitados con conocimientos, habilidades y destrezas que, en muchas ocasiones, poco tienen que ver con la formación académica que muchos estudiantes están recibiendo en las instituciones de educación superior. En ese sentido, poco se sabe sobre las percepciones de los maestros de instrumento musical, respecto a la pertinencia de esa formación artístico-musical y del rol que ellos desempeñan en ese proceso formativo. 


\section{Justificación}

Conocer las percepciones de los docentes de instrumento musical, respecto a la pertinencia y suficiencia de la formación académico-musical a nivel superior que los estudiantes están recibiendo, permite tener un acercamiento a una realidad en la que ellos mismos son protagonistas, lo que constituye una base epistemológica para promover cambios en los criterios que por tanto tiempo han regido el diseño de los planes de estudio de las carreras en ejecución musical.

\section{Objetivo general}

Generar, a partir de las perspectivas de los docentes de instrumento, un panorama relativo a la pertinencia y suficiencia de la formación académico-musical que los futuros ejecutantes están recibiendo, respecto a los retos que enfrentarán en el contexto laboral.

\section{Objetivos específicos}

1. Caracterizar las percepciones de los docentes de instrumento, tanto universitarios como de conservatorio, en lo que respecta a la pertinencia y suficiencia de la formación académico-musical que los estudiantes especializados en ejecución a nivel superior están recibiendo.

2. Describir las percepciones de esos docentes en lo que respecta a los retos que enfrentarán los futuros profesionales de la música.

3. Determinar las estrategias que, de acuerdo con esos docentes, podrían implementar los futuros profesionales de la música para superar los retos que enfrentarán.

4. Identificar diferencias importantes entre las percepciones de los profesores universitarios y los profesores de conservatorio.

\section{Metodología}

Esta investigación fue de corte cualitativo y carácter exploratorio, y se realizó con la finalidad de tener un primer acercamiento a este objeto de estudio. Para la obtención de los datos se utilizó la técnica de la entrevista semiestructurada. 


\section{Participantes}

En el estudio participaron 5 profesores del Real Conservatorio Superior de Música de Granada, España (institución con una larga trayectoria histórica) y 5 profesores de 5 programas universitarios de México (tres ellos fundados en la primera década del siglo XXI), con la finalidad de determinar, de manera tangencial, si los factores antigüedad y trayectoria institucional ejercían alguna influencia en sus percepciones.

\begin{tabular}{|c|c|c|c|c|c|}
\hline Informante & M1 & M2 & M3 & M4 & M5 \\
\hline Edad & 62 años & 45 años & 43 años & 48 años & 50 años \\
\hline $\begin{array}{c}\text { Nivel } \\
\text { académico }\end{array}$ & $\begin{array}{l}\text { Máster en per- } \\
\text { feccionamiento } \\
\text { artístico del } \\
\text { instrumento }\end{array}$ & $\begin{array}{l}\text { Doctorado en } \\
\text { Artes Musi- } \\
\text { cales }\end{array}$ & $\begin{array}{l}\text { Doctorado } \\
\text { en Historia y } \\
\text { Ciencias de } \\
\text { la Música }\end{array}$ & $\begin{array}{l}\text { Licenciado en } \\
\text { Música }\end{array}$ & $\begin{array}{l}\text { Doctorado } \\
\text { en Artes }\end{array}$ \\
\hline $\begin{array}{l}\text { Estatus } \\
\text { laboral }\end{array}$ & $\begin{array}{l}\text { Profesor } \\
\text { Titular B }\end{array}$ & $\begin{array}{l}\text { Profesor } \\
\text { Asociado B }\end{array}$ & $\begin{array}{l}\text { Profesor } \\
\text { Titular B }\end{array}$ & $\begin{array}{l}\text { Profesor } \\
\text { Asociado A }\end{array}$ & $\begin{array}{l}\text { Profesor } \\
\text { Titular A }\end{array}$ \\
\hline Institución & $\begin{array}{l}\text { Universidad de } \\
\text { Guadalajara }\end{array}$ & $\begin{array}{l}\text { Universidad } \\
\text { de Guanajuato }\end{array}$ & $\begin{array}{l}\text { Universidad } \\
\text { de Nayarit }\end{array}$ & $\begin{array}{l}\text { Universidad } \\
\text { Autónoma } \\
\text { de Aguasca- } \\
\text { lientes }\end{array}$ & $\begin{array}{l}\text { Universidad } \\
\text { Michoacana }\end{array}$ \\
\hline Instrumento & Piano & Percusiones & Guitarra & Clarinete & Canto \\
\hline
\end{tabular}

Tabla 1. Informantes de las universidades mexicanas.

\begin{tabular}{|c|c|c|c|c|c|}
\hline Informante & G1 & G2 & G3 & G4 & G5 \\
\hline Edad & 42 años & 43 años & 32 años & 30 años & 34 años \\
\hline \multirow[t]{3}{*}{$\begin{array}{c}\text { Nivel } \\
\text { académico }\end{array}$} & $\begin{array}{l}\text { Doctorado } \\
\text { en Educa- } \\
\text { ción }\end{array}$ & $\begin{array}{l}\text { Máster en } \\
\text { Educación } \\
\text { Musical }\end{array}$ & $\begin{array}{c}\text { Máster en } \\
\text { Interpretación } \\
\text { Musical }\end{array}$ & $\begin{array}{l}\text { Máster en } \\
\text { Artes espe- } \\
\text { cializado en }\end{array}$ & $\begin{array}{l}\text { Máster en } \\
\text { Música de } \\
\text { cámara; }\end{array}$ \\
\hline & & & & $\begin{array}{l}\text { Pedagogía } \\
\text { Instrumental }\end{array}$ & $\begin{array}{l}\text { Máster en } \\
\text { Interpretación } \\
\text { Orquestal; }\end{array}$ \\
\hline & & & & & $\begin{array}{l}\text { Máster en } \\
\text { Investigación } \\
\text { Musical }\end{array}$ \\
\hline $\begin{array}{l}\text { Estatus } \\
\text { laboral }\end{array}$ & $\begin{array}{l}\text { Catedrático } \\
\text { de Tiempo } \\
\text { Completo }\end{array}$ & $\begin{array}{l}\text { Catedrático } \\
\text { de Tiempo } \\
\text { Completo }\end{array}$ & $\begin{array}{l}\text { Catedrático } \\
\text { de Tiempo } \\
\text { Completo }\end{array}$ & $\begin{array}{l}\text { Catedrático } \\
\text { de Tiempo } \\
\text { Completo }\end{array}$ & $\begin{array}{l}\text { Catedrático } \\
\text { de Tiempo } \\
\text { Completo }\end{array}$ \\
\hline Instrumento & Fagot & Corno & Saxofón & Fagot & Cello \\
\hline
\end{tabular}

Tabla 2. Informantes del Real Conservatorio Superior de Música de Granada, España. 


\section{Procedimiento}

Se contactó a las autoridades de las instituciones colaboradoras, para presentarles el propósito de la investigación y solicitar su apoyo. Los directivos proporcionaron una lista con los datos de contacto de posibles participantes, a partir de la cual procedimos a comunicarnos con ellos para invitarlos a formar parte de la investigación y concertar una cita. Las entrevistas a los informantes ${ }^{1}$ del Real Conservatorio Superior de Música de Granada, España, se realizaron de manera presencial durante el mes de septiembre de 2019. Los informantes de las universidades mexicanas fueron entrevistados durante los meses de octubre y noviembre del mismo año. Durante las entrevistas se firmaron las cartas de consentimiento informado.

Para la realización de las entrevistas se siguió la recomendación de Spradley (1979) de que, a pesar de tener las preguntas preparadas, debe procurarse una entrevista lo más cercano posible a una conversación amigable. Así, el investigador mantuvo una actitud neutral y abierta, sin hacer evaluaciones, mostrando mostró una actitud de escucha activa. Se mantuvo contacto visual, otorgando todo el tiempo necesario a los entrevistados. Se hizo uso de comportamiento no verbal, principalmente, asintiendo durante la escucha.

La entrevista dio inicio con dos preguntas centrales: (i)¿cuál es su percepción respecto a las problemáticas, retos y desafíos que enfrentarán los futuros profesionales de la música?; (ii) ¿considera usted que ellos están recibiendo una preparación adecuada y suficiente para superarlos? A partir de las respuestas, la charla se redondeó con varias preguntas adicionales. La entrevista fue grabada con la ayuda de una computadora tipo tablet, y posteriormente fue transcrita con verbatim. Para llevar a cabo el análisis de los datos recopilados se utilizó la metodología propuesta por González Martínez (1999), la cual consiste de cuatro pasos o etapas:

1. Conceptualización: se identificaron unidades de análisis (pensamientos diversos y/o ideas que el informante compartió), por medio de un minucioso proceso de revisión "línea por línea".

2. Categorización: se congregó los pensamientos o ideas en grupos que las contuvieran. La rigurosidad de este proceso se garantizó mediante análisis comparativos de tipo vertical (es decir, entre las categorías derivadas de una misma entrevista) y horizontal (entre todas las entrevistas). Cuando surgieron dudas, el investigador regresó al análisis de la transcripción, a

1. Se utiliza el término "los informantes" o "el informante" para hacer alusión, al género femenino y masculino. Este criterio no tiene el propósito de demeritar las acciones encaminadas a consolidar la equidad de género, sino de facilitar la lectura y favorecer aún más el anonimato de los informantes. 
fin de reorganizar los conceptos en nuevas categorías. En este punto, el autor consideró que se había alcanzado la saturación de la información.

3. Organización: Esta etapa consistió en determinar una lógica que conectara: 1) las unidades de análisis con las subcategorías; 2) las subcategorías con las categorías; y 3) las categorías con la supercategoría.

4. Estructuración: después de organizar la información, se distribuyó y ordenó las partes en un todo, y se graficó ese todo en un mapa conceptual. Esta estructuración implicó una categorización selectiva, a fin de determinar las categorías clave que fueran necesarias y suficientes para explicar el fenómeno investigado.

\section{Resultados y discusión}

De la información proporcionada por los informantes surgió una supercategoría que se denominó: "Problemáticas, retos y desafíos del futuro profesional de la música", y cuatro categorías, tal como se muestra en la Figura 1.

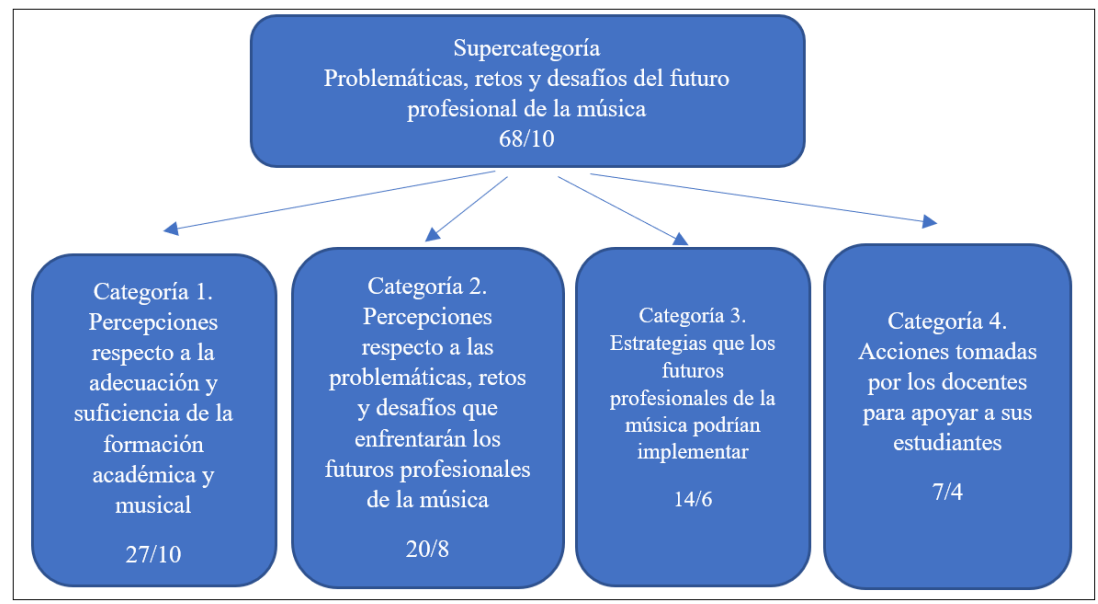

Figura 1. Categorías derivadas de la supercategoria "Problemáticas, retos y desafíos del futuro profesional de la música".

\section{Categoría I: percepciones respecto a la adecuación y suficiencia de la formación académico-musical (27//10)}

Esta categoría está conformada por 27 declaraciones emitidas por los 10 informantes, que señalan la falta de adecuación y suficiencia de la formación académica 
y musical que reciben actualmente los estudiantes especializados en ejecución, y describen algunas áreas de oportunidad o vacíos que los docentes han identificado, lo que representaría un promedio de casi 3 comentarios por informante. Por ejemplo, el Informante M1 afirmó: “...yo veo que no están, en un sentido, preparados académicamente"; mientras que el M3 aseveró: "estoy consciente de que no les estamos dando las herramientas necesarias para que puedan sobrevivir dentro de la música”. Por su parte, el Informante G2 complementó: “los conservatorios de música tienen una educación tradicional que a lo mejor, para algunas cuestiones se quedan cortas". En ese mismo sentido, el Informante G4, explicó: "yo, particularmente, pienso como que está habiendo un cambio de paradigmas ahora mismo, y me da miedo que nos estamos quedando un poco desactualizados, ciertas instituciones educativas."

Las declaraciones anteriores, quizá podrían reflejar lo que Muñoz (2018) resumió en la siguiente frase: "En la educación musical se usan metodologías del siglo XIX, impartidas por docentes del siglo XX para alumnos del siglo XXI" (párrafo 11). La cita de Muñoz no puede ser más ilustrativa. La desactualización es más que evidente, sobre todo cuando uno ve que, a pesar de los avances tecnológicos y las nuevas corrientes didáctico-pedagógicas, aún hay docentes que de manera indiscriminada se aferran a la tradición.

Los informantes señalaron algunos factores específicos que reflejan la falta de adecuación y suficiencia de la educación impartida por las instituciones en donde laboran. Así, el Informante G2 destacó la falta de conocimiento del mercado laboral para fundamentar la formación académica y musical de los estudiantes, algo que ya ha sido enfáticamente señalado por Polanco (2013), Lago y Ponce de León (2012) y Vilar (2008), entre otros. Así, el Informante G2 declaró:

Es que [el mercado laboral] no está claro, y entonces, como no está claro, nosotros seguimos formando con nuestra convicción y con tal, pero nos hacemos esa pregunta, ¿no? Si esa formación que estamos dando, es la que tendría que ser para el mercado laboral hoy en día ¿Será esa?

Por otra parte, en concordancia con lo expuesto por Danyew (2015), Guadarrama (2013, 2014), y Machillot (2018), entre otros, parece quedar claro que los estudiantes especializados en ejecución musical requieren de una formación más integral que les permita tener un mayor número de posibilidades laborales. Así, el Informante M1 explicó: "Falta que tengan más opciones de contextos o visión de esos contextos donde ellos puedan ser productivos después".

En relación a la falta de una educación integral, otros informantes señalaron como principal vacío la falta de una formación sólida en pedagogía, un aspecto que ha sido señalado por investigadores y pedagogos como Capistrán-Gracia (2019), 
Carbajal-Vaca (2017), Carmona (2018) y Chao, Mato y López (2015), sobre todo, al tomar en cuenta que la docencia musical es una de las fuentes laborales a la que más acuden los egresados de las escuelas de música para subsistir (Guadarrama, 2013, 2014; Machillot, 2018). Así, el Informante M2 aseveró: "Por ejemplo, una cosa que a mí me llama la atención es, que en una carrera de instrumentista, yo siento que falta una currícula pedagógica más sólida, o sea, enseñarles a enseñar". Del mismo modo, el Informante G2 aseveró: "El mercado laboral para la música, aquí en España, es eso... Si el 99\% del mercado laboral es la docencia, pues deberían revisar eso también.” Más aún, el Informante M4 planteó una situación bastante crítica que se vive en la institución en donde labora, y que deriva del énfasis que indiscriminadamente se le ha dado a la ejecución musical, sin considerar los cambios que se han ido originando en los contextos social, cultural, y laboral:

Yo estoy ahorita consternado porque tenemos que hacer el rediseño curricular, ante toda esta situación. Y no tenemos una planta docente de la educación musical. Hace 10 años, ipues inicias y ya!, jlo que quieres es que[el programa educativo] exista! Ahora ya existe, y ahora, de veras ¿cómo atendemos a todos estos chavos de educación musical, que son bastantes, que son la mayoría, y que si tienen ganas de aprender, pero no tenemos educadores? Yo no soy educador. Nadie en la escuela es educador ¡Nadie! Así de sencillo.

La cita anterior refleja un caso de gravedad extrema. Desgraciadamente, hay programas educativos que, debido a su reciente creación, y a su aislamiento geográfico, no cuentan aún con personal docente calificado para ciertas áreas educativo-musicales, como es el caso de la pedagogía musical. Y es que, debido al énfasis en la formación de ejecutantes, México cuenta apenas con 23 programas de educación musical a nivel superior, muchos de ellos con una matrícula extremadamente baja. (ANUIES, 2020)

Finalmente, los Informantes G1 y M4 señalaron otro vacío importante en la formación de los estudiantes: el desarrollo de conocimientos, habilidades y destrezas para conseguir trabajo, algo que está estrechamente relacionado con la gestión, y que autores como Rey-Velasco (2017) han destacado enfáticamente.

...la preparación al mundo laboral es una cosa que parece ajena a los centros educativos. Estamos enseñándoles a tocar lo mejor posible, a formarlos culturalmente, diferentes términos de historia, de estética, lo mejor posible, pero no se les prepara a que ellos después tengan como afrontar y cómo buscarse el trabajo.

Casi en los mismos términos, el Informante M4, abundó en ese aspecto: 
La universidad no da, lo que tiene que ver con un aspecto de economía. ¿Cómo voy a vender mi producto? ¿Cómo voy a vender mis servicios profesionales? Así como lo hace cualquier otro profesional, un médico, un psicólogo. ¿Cómo? Los alumnos no tienen esas herramientas. No saben cómo.

Cómo puede verse, la información recabada en cuanto a la adecuación y suficiencia de la educación que están recibiendo los futuros profesionales de la música, no nada más refleja la percepción que los docentes de instrumento tienen, sino que también da luz sobre aspectos que, de fortalecerse, podrían coadyuvar para que se tengan ejecutantes más integralmente formados, con conocimientos, habilidades y destrezas que les permitan abrirse paso en el mundo laboral del siglo XXI. Destaca, además, el grado de concordancia en las percepciones de los informantes, a pesar de pertenecer a dos ámbitos aparentemente opuestos: el universitario y el conservatoriano.

\section{Categoría 2: percepciones respecto a las problemáticas, retos y de- safios que enfrentarán los futuros profesionales de la música (20/8)}

Esta categoría incluye todas aquellas declaraciones que reflejan los retos o desafíos que, desde la perspectiva del docente, el futuro profesional de la música podría encontrar al incorporarse al campo laboral. Así, para comenzar, el análisis de la información arrojó la temática de la escasez de buena oferta laboral, lo que concuerda con Guadarrama (2013, 2014) y Machillot (2018): la falta de conciencia sobre la naturaleza del mercado laboral que realmente se está atendiendo, factor que ha sido discutido por autores como Polanco (2013) y Ponce de León y Lago (2009); y el alto nivel de competitividad del medio, ampliamente abordado por Williams (2005). Así, el Informante G2 aseveró: “el problema número uno que veo en la música hoy en día es el trabajo. Falta de oportunidades de trabajo”. En ese mismo sentido el Informante G3 advirtió el mismo reto, sobre todo en relación con el nivel técnico-musical de los egresados:

¿Hay suficiente trabajo para los egresados? ¿Cómo se presenta el panorama laboral para los próximos egresados? Pues difícil, difícil, porque en el caso de España y particularmente en Andalucía, creo que hay pocas plazas ofertadas para la calidad que tienen los estudiantes.

Por su parte, el Informante M5 señaló: “porque la problemática en el país, pues es brutal. Que vivan como ejecutantes es muy difícil". Y es que, el énfasis del concertismo en la formación musical termina por ser también una limitante, pues se convierte en el único recurso o herramienta para lograr tener un empleo y obtener ingresos, un aspecto que ha sido extensamente discutido en este artículo 
y que han abordado autores como Machillot (2018). En ese sentido, el Informante M3 señaló con bastante franqueza:

Todos recibimos la educación del concertismo, mínimo, o sea, "tu dale y tocarás". Si no tocas en Bellas Artes, aunque sea en una misa, pero cobrarás. Pero es tu única herramienta. Es la única que tienes, con un país muy competitivo.

Peor aún, en concordancia con lo expuesto por Vilar (2008), el Informante G5 destacó el hecho de que muchos estudiantes parecen adolecer de falta de iniciativa, de visión, y de realismo: "yo creo que hay un acomodamiento a no pensar, a eso .... lo que ha habido siempre: el profesor, el músico de orquesta y poco más. No te paras a pensar: ¿Y qué más posibilidades tengo?”

Para el Informante M4, y en correspondencia con el tema de la gestión cultural desarrollado por Rey-Velasco (2017), los futuros profesionales de la música se van a enfrentar a un medio en que no existe un público para la música en la que han sido formados, en el que hay mucha más demanda para otros tipos de música, y en el que tendrán que hacer sus propias propuestas:

En el mercado, hay mucha, mucha más demanda de los otros géneros que también son bienvenidos, pero nuestro reto es eso, o sea, crear gente que le pueda desarrollar el gusto o público que le pueda desarrollar el gusto a la apreciación de esta música.

Finalmente, al seguir la línea de los retos que los estudiantes podrían enfrentar en su futuro como profesionales de la música, el Informante G3 destacó la hostilidad que algunos podrían encontrar al competir por una plaza en una orquesta y mantenerla. $\mathrm{Y}$ es que, como se ha visto, el músico, dadas sus características artísticas y humanas, construye su identidad (así como su autoimagen) en base a su aptitud musical (Davis, 2010; Higuera, 2015; Netl, 1995), por lo que puede ser vulnerable a cualquier ataque a su talento. Así, el Informante G3 afirmó:

La realidad laboral es una jungla, el carácter subjetivo de la música hace que tengan que aprender diplomacia, política, modales orquestales y a la misma vez, ser intérpretes y actores a la hora de llegar a una prueba y que sea satisfactoria y poder conseguir un puesto de trabajo.

En este apartado ha quedado de manifiesto que el mundo al que se van a enfrentar los futuros profesionales de la música se caracteriza por el reto para conseguir empleo, por la demanda de músicos más versátiles, equipados con conoci- 
mientos, habilidades y destrezas diversas que les permitan ofrecer sus servicios y abrirse paso en el mundo laboral.

\section{Categoría 3: percepciones respecto a las estrategias que los futuros profesionales de la música podrían implementar (14/6)}

En correspondencia con Lago y Ponce de León (2012), varios informantes destacaron la importancia de desarrollar la creatividad, a fin de procurarse una individualidad y tener algo específico o propio que ofrecer. En ese sentido, el Informante G4 explicó:

Digamos que, el futuro que les espera, es un futuro en que ellos van a tener que mostrarse mucho más como individuos, más que las generaciones pasadas. Cada vez más, se espera del artista que aporte una audición individual, formas nuevas de hacer las cosas, formas originales, o enfoques originales. Entonces, creo que no se les está preparando de esa manera.

Del mismo modo, el Informante M4 explicó:

Entonces, que el alumno tenga claro eso, que aquí es una formación general y que ellos tendrán que, en base a sus gustos personales, desarrollar el género como propuesta de innovación, como propuesta de creatividad....

Como se ha visto en las páginas anteriores, debido a que la docencia se constituye como una de las fuentes de ingresos más accesible para los egresados de las escuelas de música, la mayoría de los docentes han coincidido en la importancia de que los estudiantes posean conocimientos en educación musical (pedagogía y didáctica). Sin embargo, se trata de un área de oportunidad que parece estar presente en los planes de estudio de las instituciones en que laboran los participantes (Polanco, 2013; Vilar, 2008). Por lo anterior, el Informante M2 señaló la necesidad de que los egresados se preocupen por capacitarse adecuadamente para la labor que deberán llevar a cabo:

Si uno ya vive y lleva una vida como músico, te das cuenta inmediatamente que uno puede tener una intuición para dar clases y para enseñar, pero sería mucho mejor si tuvieras herramientas profesionales y herramientas, digámoslo, formativas, pero de calidad, para tener un mejor desempeño y hacerte la vida más fácil a la hora de que te enfrentes a una clase de grupo o a una clase individual, tanto dentro de una institución, como siendo un maestro de clases particulares.

Más aún, para el Informante G5, incluso la docencia no es ya una opción 
viable, por lo que también destacó la importancia de ser creativo y de buscar opciones para obtener ingresos y poder subsistir: "Tú quieres ser profesor, pero, si sabes que está colapsado el sistema, ¡no te empeñes! Busca otras fórmulas de supervivencia, otras fórmulas de buscar trabajo... de generar tu propio empleo". De la misma manera, el Informante G5 reiteró la importancia de la creatividad como un factor decisivo para abrirse paso en el mundo laboral: "el alumno tiene que ser brillante en creatividad y en sentido común, como yo digo, falta mucho sentido común".

Cómo se ha visto en este apartado, la creatividad y la innovación (como producto de la creatividad) representan factores cruciales que pueden jugar roles muy importantes para que el futuro profesional de la música pueda abrirse camino en el mundo laboral del siglo XXI y desarrollarse con mayor plenitud. La Real Academia Española, en su edición 2020 (RAE, 2020), simplemente define este vocablo como: "facultad de crear". Sin embargo, la edición 1992 proporcionaba una definición más completa: "aptitud para descubrir, para imaginar y dar forma a lo inédito" (citado en Lago y Ponce de León, 2012, p. 136). Aquí radica una de las cuestiones más paradójicas en relación a los hallazgos de este artículo; en primer lugar, se sabe que la facultad de crear y la aptitud para hacerlo son innatas. En segundo lugar, la teoría y los resultados de investigación indican que la creatividad es uno de los beneficios/resultados más valorados de la educación musical (Capistrán-Gracia, 2019), sin embargo, algunos informantes señalan la falta de ella en los procesos de enseñanza-aprendizaje, lo que se ve reflejado en la falta de versatilidad para adaptarse al contexto laboral y obtener un empleo.

Lo anterior representa un llamado de atención importante. ¿Será acaso que las instituciones de educación musical a nivel superior solo se están centrando en la formación de ejecutantes que se limitan a tocar notas, sin procurar su desarrollo musical, intelectual y artístico? Según Correa-Feo (2006), para desarrollar la creatividad musical es necesario establecer un ambiente caracterizado por la ausencia de temores sociales y obstáculos académicos, así como por la motivación y la confianza en el apoyo cognitivo y afectivo externo. Por supuesto, es indispensable contar con personas bien dispuestas, que se atrevan a explorar nuevas posibilidades y a experimentar. Desgraciadamente, los comentarios vertidos por los profesores reflejan lo contrario. En ese sentido, el Informante M4 aseveró: "nuestra formación en general nos ha atacado, digámoslo de una manera, ciertos aspectos. Nos ha limitado, o nos ha quitado nuestra iniciativa y nuestra creatividad". Más aún, la información recabada indica que la falta de creatividad no solo se ve reflejada en la interpretación musical, sino también en la apertura para insertarse en el mundo laboral del siglo XXI.

En línea con lo planteado, consideramos que los comités de revisión de planes de estudio de las instituciones de educación musical a nivel superior, deben con- 
siderar la creatividad como uno de los factores más importantes en la formación del estudiante, e impulsar su desarrollo a través de todas las asignaturas, así como implementar las estrategias que sean necesarias para lograrlo. No se debe olvidar que, más allá de la formación musical de alto nivel, la educación, en cualquier ámbito, debe de procurar el desarrollo del pensamiento crítico y reflexivo de los estudiantes, así como la capacidad para resolver problemáticas en contextos reales, algo que es crucial para abrirse paso en la vida.

\section{Categoría 4: acciones tomadas por los docentes para apoyar a sus estudiantes (7/4)}

La última categoría recoge las declaraciones relacionadas con estrategias y acciones implementadas por los docentes, para apoyar la formación de sus estudiantes y atender las áreas de oportunidad que dejan los planes de estudio de las licenciaturas en ejecución. Así, por ejemplo, el Informante G3 afirmó haber tomado acciones precisas para desarrollar actitudes positivas y valores humanos en los estudiantes de la academia de saxofón, algo que, según Parra (2003), está muy de acuerdo con las necesidades de formación integral actuales. Así, ese Informante explicó:

El año pasado comenzamos un proyecto muy concienzudo, en el que ellos vieron que el conservatorio es su lugar, su familia, es su casa, y que todo lo que concierne al trabajo de aquí debe ser de respeto, educación y trabajo, y mucha implicación a la hora de estudiar. Desde el año pasado y este año, pude dejar una copia del modelo que he entregado a todos los alumnos del aula. Por ser el catedrático, me considero un poco con la responsabilidad de que todos los profesores de la disciplina de saxofón partamos de un mismo punto, y se incluyan valores de respeto, tolerancia, democracia, aportación de ideas. Que hagamos mesas redondas en las que a partir del trabajo en conjunto todo mundo lleguemos al mismo destino.

Muy en sintonía con Lago y Ponce de León (2012), el Informante G4 señaló haber implementado estrategias para impulsar a los estudiantes a salir de los esquemas conservatorianos de formación instrumental, y promover el desarrollo de la creatividad, por lo que explicó: “...yo intento, como que mis clases cada vez sean menos burocráticas, menos cuadradas o cuadriculadas, y exigirle al alumno un poco de creatividad". Por otro lado, el Informante M3, en función de la convicción que tiene en cuanto a la importancia de ampliar el número de herramientas con que debe contar el futuro profesional de la música, señaló:

Ahorita he dejado casi de dar guitarra, por dar investigación musical, por dar esa herramienta que les va a hacer falta; porque si ellos saben de investigación musical, 
pueden hacer un documento para la gestión, pueden escribir un artículo, pueden tener otro panorama. En otras palabras, tienen una herramienta más.

Cómo puede verse, cuatro de los diez informantes compartieron las estrategias que utilizan para cambiar, aunque sea un poco, la realidad de la situación educativa, algo que, desde la perspectiva del investigador, refleja la vocación y el compromiso de los docentes, y es que, como explicó el Informante G2: “entonces, también puedo hacer una crítica a los planes de estudio, porque nosotros tampoco tenemos influencia sobre eso. Ahí está la administración atrás ¿y qué puedo hacer? ¡Nada! Ahí están los planes de estudio que no contemplan eso”.

\section{Conclusiones}

El estudio permitió alcanzar completamente los objetivos de investigación. Así, fue posible identificar las percepciones de los maestros de instrumento, respecto al nivel de pertinencia y suficiencia de la formación académico-musical que los estudiantes especializados en ejecución están recibiendo; se caracterizaron los retos que posiblemente enfrentarán los futuros profesionales de la música, y se describieron algunas de las estrategias que podrían implementar para superar los retos que enfrentarán. Más aún, se determinaron algunas acciones implementadas por los informantes para apoyar y redondear la formación de sus estudiantes.

Los entrevistados, docentes de instrumento tanto en el contexto universitario como en el conservatoriano, y sin mediar en lo absoluto la antigüedad y la trayectoria institucional, coincidieron en que los planes de estudio en música están afianzados en modelos del siglo XIX, y estuvieron de acuerdo en que procuran la formación de ejecutantes, quienes, en su gran mayoría, no encontrarán un espacio en el mundo de la música de concierto, por lo que tendrán que buscar otras opciones laborales e incluso, combinarlas para poder subsistir. Del mismo modo, consideraron que los currículos debían de ajustarse a las necesidades del siglo XXI y enfatizar áreas como la educación musical, la investigación, la gestión cultural, la formación de públicos y la innovación, de tal manera que los contenidos de las asignaturas contribuyan a la formación de músicos académicos versátiles, capaces de atender el mercado laboral actual y vencer los retos y desafíos que entraña.

De la información recabada, se destaca la función crucial de la creatividad, como factor que permite a los estudiantes desarrollar su pensamiento crítico y reflexivo, abrirse a nuevas posibilidades para encontrar soluciones a las problemáticas que enfrenten y construir su propio futuro.

Más aún, los resultados parecen indicar que se está gestando un cambio en la idiosincrasia del músico académico. En trabajos como los de Carbajal-Vaca 
(2017), De la Rosa-Priego (2013), y Capistrán-Gracia (2019), entre otros, se ha destacado la resistencia de muchos docentes a entender y aceptar nuevos modelos educativo-musicales que promuevan una formación más integral. Incluso, algunos maestros llegan a ejercer una influencia negativa en los estudiantes, al convencerlos de que la formación de concertista debe prevalecer sobre cualquier otra. Sin embargo, este estudio parece apuntar en una dirección distinta. Los docentes entrevistados, la mayoría de ellos habilitados con posgrado, mostraron una preocupación sincera respecto a la educación académica y musical que sus estudiantes están recibiendo, y coincidieron en la mayoría de sus percepciones respecto a la necesidad de promover cambios importantes en su formación.

Esta investigación representa apenas un pequeño acercamiento a este objeto de estudio, y exhibe algunas áreas de oportunidad que deben ser tomadas en cuenta. Para empezar, la "muestra" seleccionada es muy pequeña y, aunque la diferencia de edades no parece haber ejercido influencia, las coincidencias en las percepciones de los docentes podrían deberse a la formación humanista de alto nivel que la mayoría ha recibido. Por lo anterior, se considera que es crucial ampliar este tipo de estudios, a fin de diagnosticar la situación actual con mayor precisión y proponer cambios que se vean reflejados en planes de estudio más objetivos y realistas, en programas dirigidos a atender el mercado laboral y satisfacer las necesidades sociales. Solo así se realizará una contribución importante a la formación integral de nuestros estudiantes, de cara a las problemáticas, retos y desafíos que enfrentarán en el mundo laboral de este siglo XXI.

\section{Referencias}

ANUIES. (2020). Anuarios Estadísticos de Educación Superior. http://www.anuies.mx/ iinformacion-y-servicios/informacion-estadistica-de-educacion-superior/anuarioestadistico-de-educacion-superior

Capilla, L. (2000). Vocación profesional, frustración y militancia. Acontecimiento: órgano de expresión del Instituto Emmanuel Mounier, 54, 47-48. http:/ /www.mounier.es/revista/ pdfs/054047048.pdf

Capistrán-Gracia, R.W. (2019). Educación Musicaly Bienestar Psicológico. Resultados de Investigación, Diseño de la Intervención e implicaciones para la educación. Aguascalientes, México: Editorial UAA. https://editorial.uaa.mx/catalogo/cac_rc_musical_psicologico_9786078714353.html

Carbajal-Vaca, I. S. (2017). Educación musical superior: el desarrollo de competencias profesionales en músicos universitarios. En Memoria Electrónica del Congreso Nacional de Investigación Educativa COMIE (pp. 1-12). San Luis Potosí, México: COMIE. http:// www.comie.org.mx/congreso/memoriaelectronica/v14/doc/0081.pdf 
Carmona, J. (28 de diciembre de 2010). Red Educativa Musical. Música: posibilidades laborales y oficios [Publicación de blog]. http://recursostic.educacion.es/artes/ $\mathrm{rem} /$ web/index.php/es/dossier-educativo/item/301-m\%C3\%BAsica-posibilidadeslaborales-y-oficios

Chao, R., Mato, M. D. y López, V. (2015). La formación musical del profesorado especialista en los CEIP gallegos. Revista Portuguesa de Educação, 28(2), 111-131. https://www. redalyc.org/pdf/374/37443385006.pdf

Correa-Feo, J. P. (2006). Reflexiones sobre la cognición en la creatividad musical. Anuario, 29, 402-422. http://servicio.bc.uc.edu.ve/derecho/revista/idc29/art13.pdf

Danyew, A. M. (2015). Piano Class for the Real World: Exploring Experiential Learning with a Collaborative Inquiry Group in a Creative Musicianship Lab (Disertación doctoral no publicada). Eastman School of Music.

Davis, J. A. (2010). Classroom Discussion and the Community of Music Majors. Journal of Music History Pedagogy, 1(1), 5-17. https://www.ams-net.org/ojs/index.php/jmhp/article/ view/8

De la Rosa-Priego, E. A. (octubre/2013). Tres problemas para la educación musical profesional. Ponencia presentada en el Encuentro Nacional de Educación Artística Superior. Aguascalientes, México.

González Martínez, L. (1999). La sistematización y el análisis de los datos cualitativos. En: Mejía, A. R. y Sandoval, A. S. [oord.]. Tras las vetas de la investigación cualitativa (pp. 157 173). ITESO.

Guadarrama, R. (2013). Mercado de trabajo y geografía de la música de concierto en México. Espacialidades. Revista de temas contemporáneos sobre lugares, política y cultura, 3(2), 192-216. https://www.redalyc.org/pdf/4195/419545120007.pdf

Guadarrama, R. (2014). Multiactividad e intermitencia en el empleo artístico. El caso de los músicos de concierto en México. Revista Mexicana de Sociologia, 76(1), 7-36. http:// www.scielo.org.mx/scielo.php?pid=S0188-25032014000100001\&script=sci_abstract

Higuera, M. G. (2015). Acciones socio-educativas de las orquestas sinfónicas españolas y de Gran Bretaña [Tesis doctoral no publicada]. Universidad del País Vasco. https://addi.ehu. es/handle/10810/16009

Lago, P. y Ponce de León, L. (2012). Creatividad y tecnología en la orientación de nuestros futuros músicos. Revista Iberoamericana sobre Calidad, Eficacia y Cambio en Educación, 10(2), 136-147. https:// revistas.uam.es/reice/article/view/3060 
Machillot, D. (2018). La profesión del músico, entre la precariedad y la redefinición. Sociológica (México), 33(95), 257-289. http://www.scielo.org.mx/scielo.php?script=sci_ arttext\&pid $=$ S0187-01732018000300257\&lng=es\&tlng $=$ es.

Muñoz, D. (2 de abril de 2018). David Tuba. Retos de la educación musical del S. XXI [Publicación de blog]. https://blog.davidtuba.com/es/educacion/retos-de-la-educacion-musical-del-s-xxi

Nettl, B. (1995). Heartland Excursions: Ethnomusicological Reflections on Schools of Music. University of Illinois Press.

Parra, J. M. (2003). La educación en valores y su práctica en el aula. Técnicas Pedagógicas, 8, 69-88. file:///C:/Users/PC/AppData/Local/Temp/Dialnet-LaEducacionEnValoresYSuPracticaEnElAula-1012022-1.pdf

Polanco, R. (2013). La orientación académica y profesional en los Conservatorios de Música. ArtsEduca, 5, 1-7. file://C:/Users/PC/AppData/Local/Temp/DialnetLaOrientacionProfesionalAplicadaALasEnsenanzasProf-6126456.pdf

Ponce de León de León, L. y Lago, P. (2009). Necesidades de orientación en los conservatorios profesionales de música. Revista Electrónica de Leeme, 24, 63-76. https:/ / ojs. uv.es/index.php/LEEME/article/view/9795

RAE. (1992). Creatividad. En Diccionario de la Lengua Española (21 ${ }^{\mathrm{a}}$ ed.).

RAE. (2020). Creatividad. En Diccionario de la Lengua Española (23a ed.). https://dle.rae.es/ creatividad? $\mathrm{m}=$ form

Rey-Velasco, E. (2017). Gestión cultural aplicada a la música independiente. Estudio de caso en Cali y Medellín Colombia. ArtsEduca, 17, 126-149. https://www.e-revistes.uji. es/index.php/artseduca/article/view/2564

Spradley, J. P. (1979). The ethnographic interview. Harcourt Brace Jovanovich College Publishers.

Vilar, J. M. (2008). Jóvenes músicos, formación académica y mundo laboral. Musiker, 16, 341-350. https://core.ac.uk/download/pdf/11502464.pdf

Williams, K. (2005) Reshaping Dreams: "A Life with Music" or "A Life in Music”? American Music Teacher, 55(2), 71-73. http://eds.b.ebscohost.com.dibpxy.uaa.mx/eds/ pdfviewer $/$ pdfviewer?vid $=2 \&$ sid $=8$ b53a420-f944-4415-97d1-6b35a887da70\%40pdcv-sessmgr02 